\title{
Persuasive Strategies on Social Media: A Case of Malaysian Social Media Influencer Asma Nasarudin
}

\author{
Norrabiyah Ithnin, Nur Hazwani Mohd Muhridza*, Siti Rahmah \\ Abdullah \& Siti Noraisyah Jamal \\ Language Academy, Faculty of Social Sciences and Humanities, Universiti Teknologi Malaysia, 81310 UTM \\ Johor Bahru, Johor, Malaysia \\ Nur Afifah Mohd Rosli \\ Kolej Professional Mara, Jalan Ungku Abdul Aziz, Bandar Penawar, Johor, Malaysia
}

Submitted: 31/10/2019. Revised edition: 26/11/2020. Accepted: 26/11/2020. Published online: 30/12/2020

\begin{abstract}
Social media influencers, or SMIs are on the rise in this age of ubiquitous Internet. SMIs as independent third-party endorsers utilise platforms such as social media, blogs, etc. to influence the attitudes of their audiences. SMIs have a powerful role in promoting or demoting a brand and/or organization to their followers as they can influence perceptions and even the purchasing power of their audiences. This phenomenon is obvious from the resonance of social media users with SMIs reviewing products, services and social trends on their social media accounts. SMIs document or visually narrate what they do in their daily life via photo and video-sharing applications in social networking sites (SNS) such as Instagram and YouTube. In order to become a 'micro celebrity', the influencers embed commercials and celebrity culture into their postings. This study aims to investigate the persuasive devices used by one Malaysian social media influencer through her social media postings using the five elements in the Electronic Eloquence Model (EEM). A thorough qualitative analysis was conducted to identify the strategies implied within the embedded media content of Malaysian SMI Asma' Nasarudin. The data selected for analysis were gathered from her Instagram and YouTube video postings from October 2018 to December 2018. A total of five postings were carefully selected. Textual and visual analyses were conducted to investigate the persuasive strategies and devices. Findings demonstrated that all five elements of EEM appeared in the social media postings.
\end{abstract}

Keywords: Persuasive Strategies, Social Media Influencers (SMI), Electronic Eloquence Model (EEM)

\section{INTRODUCTION}

Social media influencers or SMIs are individuals who have created a reputation due to their niche on a particular topic. Freberg, Graham, McGaughey and Freberg (2011) state SMIs as third-party endorsers who utilize platforms such as social media, blogs, etc. which often have an impact on their followers' attitudes. To some extent, their influence can have a role in encouraging or discouraging

*Correspondence to: Nur Hazwani Mohd Muhridza (email: nurhazwani@utm.my) 
followers to purchase a particular product or brand as they are seen as a credible source to offer advice and thus can influence public perceptions and views.

Freberg et al. (2011) defines SMIs as a group of people who have the power to change, influence and affect other people's belief or attitude through blogs, tweets, and other social media platforms; third party endorsers. The expected self-attributions to be acknowledged and verified as SMIs incorporate the following characteristics: good credibility, high activity, distinct brands, large followings, and great exposure (Ioanid, Militaru \& Mihai, 2015). Speaking of the large followings, where one has a huge number of followers or fans, is one of the vital characteristics for that person to be acknowledged as Social Media Influencers. According to La Casa, de la Fuente, García-Pernía and Cortés (2017), fans are the type of people who possess a positive emotional connection with something, or someone widely known and show the delighted feeling by acknowledging the celebrity or a famous person's style or creativity.

Rettburg (2014) proposes that self-presentation is a construction of identity through both textual and visual platforms. In modern society, the idea of self-representation enables SMIs to make documentation or visually narrate about what they do in their daily life. According to Dobson (2015), when compared to real face-to-face self-representation, one can be more conscious and reflective through the text and images he or she posted on media as it symbolizes who they are. However, Marwick (2015) argues that self-representation can be a business strategy as it can be very stylized and profitable like what most influencers on Instagram currently practice and share with their followers.

For the past few years, the internet and social media are seen to be significant in removing the barriers of traditional word of mouth (O'Brien, 2011) to make way for more instantaneous communication. Social media platforms such as Instagram, Facebook, Twitter and Youtube have become a trend for various purposes be it marketing (Aral, Dellarocas \& Godes, 2013) or self-branding (Chen, 2013). Malaysians are regarded as one of the most active Instagram consumers in the Asia Pacific region, according to Lee (2016), and it is common not only among adolescents and young adults, but also among older adults. People are now focusing on online platforms to look for purchasing necessities, product reviews as well as a sense of inspiration from the abundance of social media influencers (Marwick, 2015). Hence, this study aims to examine the persuasive elements utilised by SMIs in their social media postings with a focus on one of Malaysia's top SMI.

\section{BACKGROUND OF STUDY}

Micro-celebrity is also known as social media influencers (Chae, 2017). SMIs can be anyone whether unpopular actors or models, celebrities' friends, rich individuals that have high-end items or pretty students (Marwick, 2015). Interestingly according to Saul (2016), influencers possess what their followers wish to have. Most importantly, successful influencers are able to attract their followers with a good sense of humour, common characteristics and having their individual's perspective. In fact, Marwick (2015) pointed out that postings shared by SMIs are perceived as young people's catalog 
because that is the life they dream of having. This is because according to Abidin (2016), SMIs do not only expose their identity, but also expose their daily routines to thousands of followers.

According to Tengku Siti Aisha Tengku Mohd Azzman Shariffadeen and Aini Maznina A. Manaf (2019), social media users who follow celebrities on Instagram consequently have the chance to establish a bond with their admired celebrity by watching their videos, commenting on their posts and enjoying their pictures. Thus, by communicating their lifestyle to their fans, a well-known media figure can significantly affect and influence their followers through celebrity-fan involvement and engagement on social media. They added, particularly in Malaysia, celebrities such as Siti Nurhaliza, Noor Neelofa, popular entrepreneur Vivy Yusof and the renowned social media figure, Hanis Zalikha, have a strong impact in determining current fashion trends. Overall, these celebrities and important media figures have created a powerful following of social media and can also be regarded as influencers. Hence, the findings of their study indicate that female Instagram users in Malaysia tend to follow both traditional celebrities; singers, actresses, radio DJs and non-traditional celebrities; social media influencers where Instagram and Twitter seem to be the most preferable platform for them. Therefore, this paper aims to exemplify some persuasive strategies used by a selected SMI in attracting her followers. This is pertinent as self-representation on social media platforms is seen to be a key factor for an individual to position themselves in the digital media. The focus of this study is to examine her sharing about faith and belief, in relation to Islam. It is interesting to see how she carries herself as a Muslim influencer while embedding motivational messages within her postings.

\section{METHODOLOGY}

This paper attempts to investigate a Malaysian social media influencer Asma' Nasaruddin, also known as Asma' Nasa. To have a sense of Asma' Nasa's internet popularity, she has 8,761 subscribers on her YouTube channel, and 113k followers on her Instagram account (as of November 2018).

Data generation was undertaken in a period of two months, from October 2018 to December 2018. The desired postings were carefully selected to enable the researchers to scrutinize the data for subsequent analysis. Hence, purposive sampling was adopted in the data collection process. The following criteria for selection used during the data selection procedure: (1) content relevance-the postings should discuss about the sharing of lifestyle, particularly on religious topics or issue; (2) posts that are not related to promoting or advertising any products or brands; (3) posts can be in the form of photos or videos.

The data were then analyzed through the lens of Electronic Eloquence Model (EEM) by implementing both textual and visual analysis. Textual analysis allowed the researchers to look beyond the text and make meaningful interpretation. Visual analysis offers researchers an interdisciplinary method for understanding and contextualizing images. By connecting images to the context of consumption, researchers gain a more thorough understanding of how images embody and express values and ideas. The selected data were categorized into the five elements of Electronic Eloquence Model (EEM) accordingly. 
With regard to potential ethical concerns, literature on internet research ethics acknowledges three main views. First, an open-source approach views all publicly available/accessed Internet content as fair use and do not infringe on privacy or copyright matters (Hookway, 2008; Hewitt-Taylor \& Bond, 2012). Thus, the author's permission is not required if their work were to be assessed by others.

\section{ANALYTICAL FRAMEWORK}

\section{Multimodal Discourse Analysis (MDA)}

Multimodal discourse analysis (MDA) takes on a paradigmatic shift from studying language structure and functions alone to the study which combines language and semiotic resources such as images, sounds, and gestures (O’Halloran, 2011). Language is analysed beyond layers of words, phrases and clauses and extends to how an image can exemplify meaning to its viewers. MDA also functions to define a diverse range of approaches for studying how social actors produce meaning through the interaction with other social actors and their environments (Pirini, Matelau-Doherty \& Norris, 2018). Such meaning-making resources assist in producing a strong and contextually driven approach when texts and images are combined thus, affects the characterisation of communicative effects (Wignell, Chai, Tan, O'Halloran \& Lange, 2018). Generally, language in the form of captions and semiotic resources such as images, visuals and audio make up the entirety of social media platforms. Therefore, MDA is seen to be a significant approach to explore this study.

\section{Electronic Eloquence Model (EEM)}

The Electronic Eloquence Model (EEM) proposed by Jamieson (1988) is adopted as the main analytical tool of this study. As discussed by Wan Hanafi, Ithnin and Ab. Rashid (2017), this model fits the analysis of this study as it provides a useful perspective in understanding how people persuade in online settings. Jamieson comes up with this model due to the changing in the pattern of persuading people in the media age. The model consists of five elements which are personification, self-disclosure, conversational style, synoptic and visual dramatization. The five elements in EEM are discussed in the following paragraphs.

The first element in EEM is personification, where persuaders use this element to personify and provide imagery to represent their ideas and opinions. Personification prompts the audience to use their imagination to picture the message the persuader is conveying. Borchers (2013) claimed that a persuader is able to build intimacy with the audience by making use of an individual or particular object to represent their idea or message-persuaders can tell stories and use imagery to appeal to the audience's feelings. The impact of persuasion is enhanced as the message becomes alive in the audience's minds.

Self-disclosive is the second element in EEM. It employs storytelling and narrative about persuaders' own experiences-assist the persuasion process as the persuaders reveal the story behind their personal belief and "it encourages dramatic narratives that audiences accept as proof for a 
persuader's claim" (Borchers, 2013). According to West and Turner (2010), the Narrative Paradigm theory developed by Walter Fisher highlighted that narration is an effective device for the better understanding of human behavior as it unfolds particular events and problems encountered.

The next element is conversational style which explains the use of informal style of writingwhich is common in the context of social media content. Conversational style, according to Borchers (2013), refers to how the words in speech are used as well as the way those words are presented to the audience. The approach requires a technique of resorting to simple vocabularies and avoiding the use of jargon or bombastic words in order not to confuse and mislead the audience which will reduce the audience's attention and interest. As pointed out by Fahnestock (2011), the usage of pronouns such as ' $I$ ' and 'we' create a sense of personal in stories. They are articulated in the context of their occurrence-the writing style appears to be relaxed, approachable and elaborative. By adopting conversational style, the writing becomes casual and engaging, and this gives a space for the readers to be united with the writer.

Synoptic is the fourth element in EEM where the persuaders use short and concise phrases to summarize the whole idea. This element includes synecdoche and verbal distillation. Synecdoche is a figure of speech used to capture a part of the meaning as a whole-summarize the whole idea. Jamieson (1988) asserted that eloquent persuaders have the ability to synopsize an issue in a clear, concise and dramatic statement. As postings on social media are usually limited to a certain duration or file size, for example, the videos posted on YouTube and Instagram, this element can be regularly seen in the setting.

The last element is visual dramatization, or also known as visual rhetoric. According to Jamieson (1990), images in visual rhetoric carry trustworthiness and newsworthiness as the moment captured in the images provide eternal evidence and help to create a memorable vignette in audiences. Visuals on social media are a compulsory tool of attraction, hence it is a matter of concern among social media influencers.

\section{Data Analysis and Discussion}

Based on the analysis of selected postings, which were categorised based on the five persuasive devices adopted from the Electronic Eloquence Model (EEM), the findings showed that the postings analysed in this study used all five persuasive devices as outlined in EEM.

\section{Personification}

The first persuasive devicefound in the postings analysed is personification. This device is an element to personify and provide imagery to represent the persuader's ideas and opinions. Extract 1 is presented to exemplify how personification strategy is employed in Asma' Nasa's posting. Figure 1 shows a photo of a random building in London with some flowering trees. 

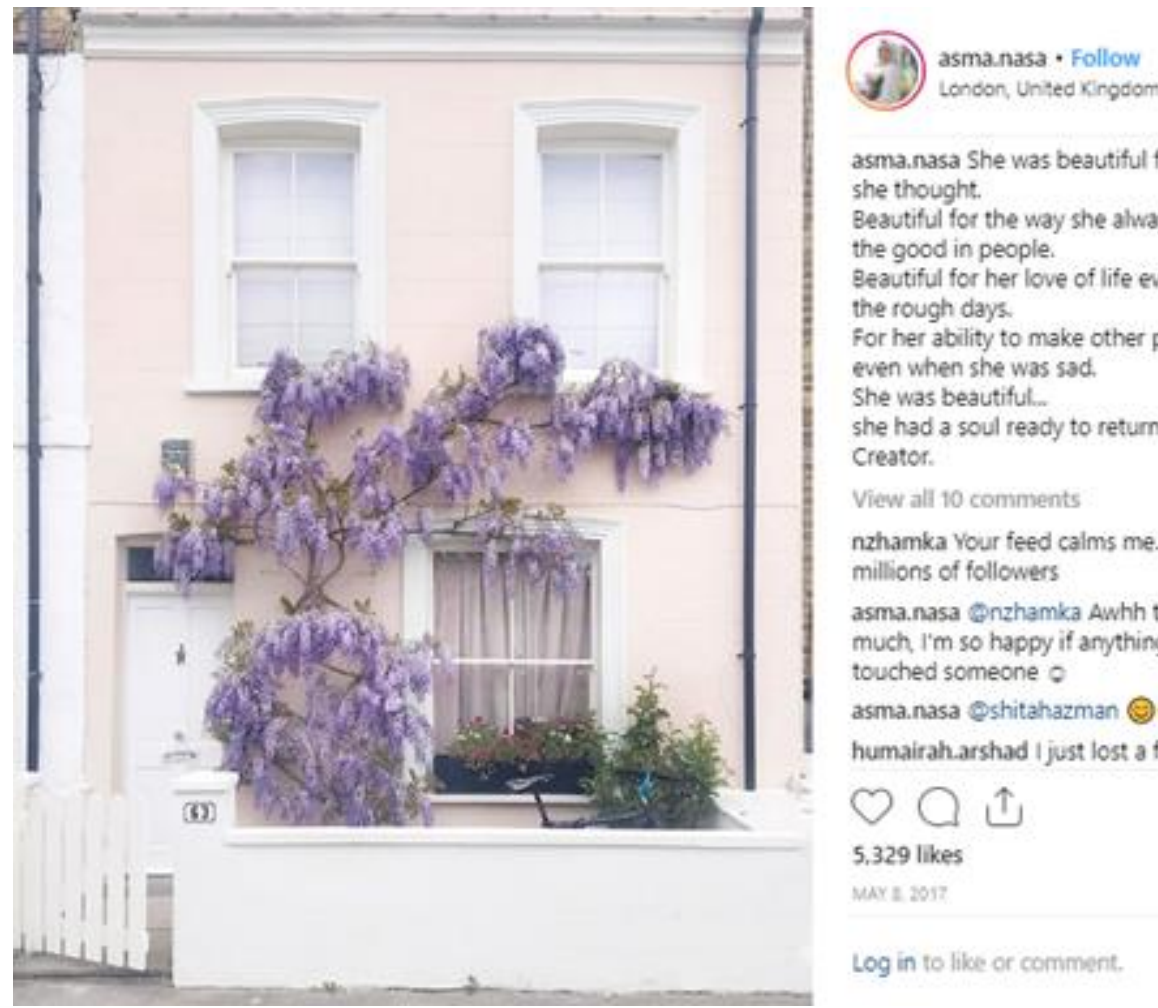

asma.nasa She was beautiful for the way she thought.

Beautiful for the way she always looked to the good in people.

Beautiful for her love of life even through the rough days.

For her ability to make other people smile, even when she was sad.

She was beautiful..

she had a soul ready to return back to her Creator.

View all 10 comments

nzhamka Your feed calms me. You deserve millions of followers

asma.nasa @nzhamka Awhh thank you so much I'm so happy if anything i share touched someone $Q$

asma.nasa (shitahazman (:)(2)

humairah.arshad I just lost a friend today

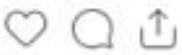

5,329 likes

Mara agr?

Log in to like or comment.

Figure 1 Screenshot of Asma's Instagram page

Extract 1 shows an excerpt of the caption used by Asma' from Figure 1.
Extract 1
$1 \quad$ She was beautiful for the way she thought.
$2 \quad$ Beautiful for the way she always looked to the good in people.
$3 \quad$ Beautiful for her love of life even through the rough days.
$4 \quad$ For her ability to make other people smile, even when she was sad.
$5 \quad$ She was beautiful...she had a soul ready to return back to her Creator.

In Extract 1, Asma' acts as a narrator and totally implements the second person point of view by using the pronouns she and her. Asma' tries to entail the concept of poetic composition in her writing - as if she is describing and narrating about someone. The caption written by Asma' as a whole falls under the umbrella of personification strategy from the Electronic Eloquence Model (EEM) by Jamieson (1988) — as explained in the previous section. This can be seen from the way Asma' uses an individual to embody the ideas of the persuader's message - in this case, the individual is represented as 'she'. According to Borchers (2013), when persuaders tell stories of individuals, they 
are personifying the values of the intended message and also creating a relationship with the audience because the audience sees them as caring about the needs and values of the individuals they cite. The way Asma' designs her writing requires the readers to interpret or look into the message pragmatically - taking into consideration the context that Asma' is trying to focus on or speak about. She prompts the readers to use their imagination to picture the message she tries to convey. Ab et al. (2016) stated that personification allows the message to become alive in the audience's minds and thus enhancing the impact of persuasion-building intimacy with the audience as persuaders can tell stories and use imagery to appeal to the audience's feelings. Asma' chooses to highlight a certain topic; in this case, the good qualities of a human being, but how she managed to put it into a nicely structured portrayal has underlying her persuasive motive to induce the hidden note among the readers.

Moreover, it is not merely through the caption, yet Asma' also has injected the imagery element in her posting which is figuratively expressed through the representation of blossomed and beautiful Wisteria flowers. The picture of $\mathrm{W}$ isteria flowers covered a quarter of the wall and made it seem really peaceful and full of serenity. Wisteria is famously known for their lovely and mesmerizing looks and could undeniably attract and capture her followers' attention. It is found relatable when Asma' makes a connection between the picture and the caption as she utilizes the female pronoun; "she' in the caption. As women always being symbolized as flowers and vice versa, the connotation between these two are certainly on the account of their shared features and characteristics, hence it makes them reciprocally connected between each other. This is supported by Arbit (2010) where the notion of female sexuality has always been symbolized by flowers throughout the history of all over the world. Meanwhile, Ehnenn (2008) opines that traditionally, people have viewed females as "inhabiting the realm of Flora-Flora herself being a female deity" for the reason that there was a conviction that females shared the characteristics of beauty, fragility, idleness, ornamentally and passivity with flowers.

Lakoff and Johnson (1980) have described that, in cognitive metaphor research, personification as an ontological metaphor involves a cross-domain mapping in which an object or entity is further specified as an individual. Asma' has employed prosopopoeia type of personification where Hamilton (2002: 411), defines it as when authors used the voice of another person or object in addressing their audience, just like how she has demonstrated the image of $\mathrm{W}$ isteria flowers and the female pronoun in her posting. On the other hand, with regard to such allegorical personification on female representation, Crisp (2005) indicated that, in the case of such abstract personification, an abstract noun refers to a character in a fictional situation through a metaphorical pragmatic connector, by which readers can get the whole idea of her posting by making a logical connection between the caption and the photo. As this aspect strongly correlated with her followers' emotional attraction, they tend to put themselves in the SMI's caption and eventually the effect of persuasion increases with the message becoming alive in the minds of the audience.

\section{Self-disclosive}

The second persuasive device found in the postings analysed is self-disclosive which employs storytelling and narrative about persuaders' own experiences. Extract 2 and 3 are presented to 
exemplify the self-disclosive strategy. Figure 2 shows a screenshot of a video posted by Asma' on her YouTube channel. The video entitled LIFE AFTER MARRIAGE, SPIRITUAL LOWS \& HAPPINESS with a duration of 19:52 minutes has recorded 30,346 views. In the video, Asma' shares her personal stories to update her followers regarding her current life. She also inserts some enlightening discussion about spiritual talks as an inspiration.

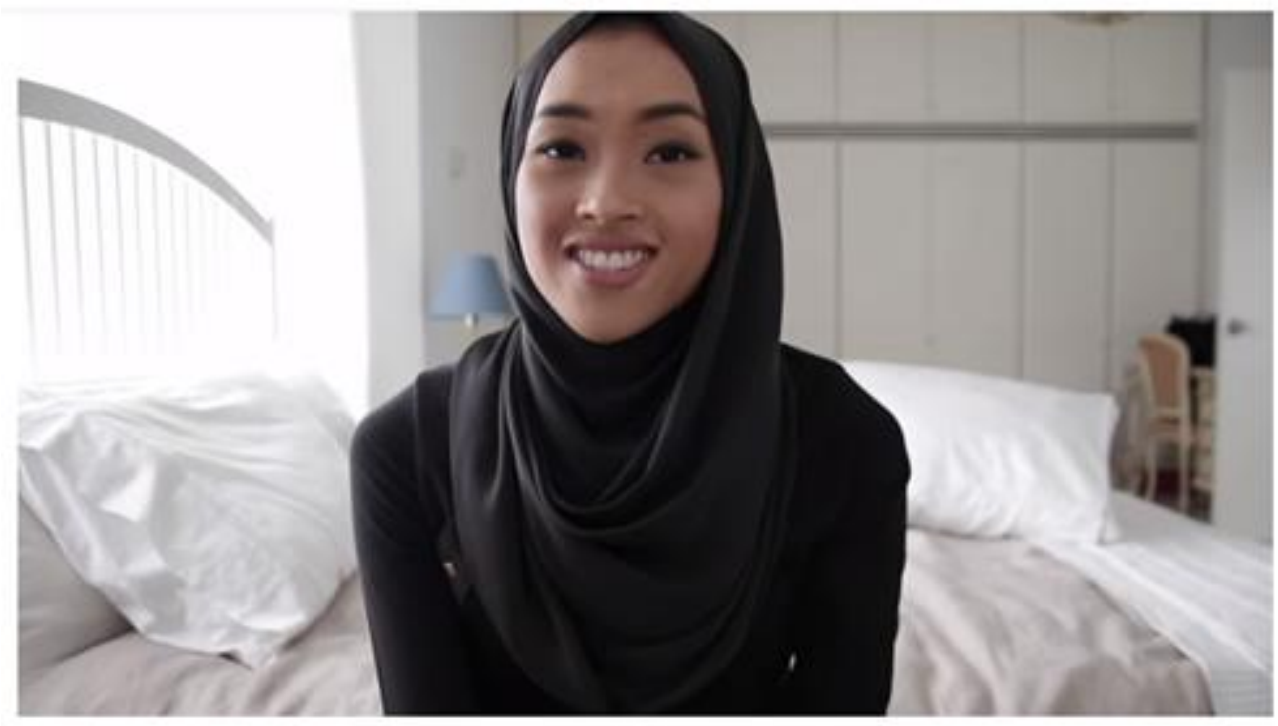

LIFE AFTER MARRIAGE, SPIRITUAL LOWS \& HAPPINESS I Asma' Nasa

Figure 2 Screenshot of Asma's video from YouTube

Extract 2 shows an excerpt of what has been spoken by Asma' from Figure 2.

\section{Extract 2}

1 The first two months that I was sleeping in my faith like I thought my Iman must go down and down...

2 because...because when I was single I used to have a very different routine you know...

$3 \quad$ like I will wake up early and pray and then read Quran and then like listen to Tafsir and then you know either do some blogging or vlogging in the morning, writing and all of that, reading... 
but after I got married like things have changed...I just realized like I was going with kind of like a new rhythm... hugs...yeah and so...hehehe...yeah and you know like I...I mean honestly I'm just gonna be open about it... and then I wasn't reading as much Quran...I...I don't know I just kind of became bit more lack towards a certain things that I was very like routined about before... when I was still single.

6 And...for the longest time, I actually got a little bit mad and I was like...you know what...since I got married, I'm not myself anymore... and I thought I lost myself...

In Extract 2, Asma' totally utilizes her personal life story as the main content-this is due to the vlogging concept where users have the freedom to set their topic and media content. The first personal pronouns such as $I$ and $m y$ are mostly employed. It is clearly seen in this video that Asma' employs the self-disclosure strategy from the Electronic Eloquence Model (EEM) by Jamieson (1988). West and Turner (2010) mentioned a communication theory named Narrative Paradigm by Walter Fisher (1984)_Fisher suggests that telling the story or narration is an effective device for the better understanding of human behaviour as the act of sharing experiences unfold particular events and problems encountered, enabling the audience to analyse rhetoric. This can be seen in the whole Extract 2 (line 1 to 6) where Asma' presents her narration in a manner or sequence that builds the argument from least important to most-chronologically organized. Self-disclosive employs storytelling and narrative about persuaders' own experiences.

Extract 3 is a continuation of the same content as in Figure 2.
Extract 3
1
I had a talk with my sister as well and she...she made me feel at peace as well because I was like...you know I thought I was kind of sleeping away...losing my faith you know...I'm like going on low with my spirituality and...
2 she's like...look, chill out, chill out, chill out girl...you're not...
3 my sister reminded me that like...look, all these extra things you used to do spiritually like you know...say for example pray Sunat and all that, doing extra extra things and all that, it's good you know...but she says like...when you're married, like...you do other things where you can get extra brownie points with
God. You know, when you do all of that with your husband so easily...
4 and I was like...haaaaa yeah I never thought to look at it in that way...

In the same video, Asma' then continued her storytelling to further explain her situation. Extract 3 shows the part where Asma' shares how she refers to her sister (line 1) regarding the issue that she had. This can be perceived as convincing and somehow trustworthy because Asma' makes reference to someone who is reliable and might have previously experienced the same thing, someone who is credible enough for her to seek advice- her sister. She also repeats some phrases like chill out (line 2) to show emphasis and strength to that point. It is then followed by the resolution part of the story, 
where Asma' actually delivers it in a 'constructed dialogue' (Lucas, 2001) by her sister (line 3)making the story come alive and thus building curiosity among the viewers.

In Extracts 2 and 3, it can be seen that Asma' puts forth her 'prescriptive beliefs' (Stiff and Mongeau, 2003), that is, a subjective statement regarding the appropriateness of an action in a given situation. This belief reflects the morals, ethics and values of the persuader and it cannot be viewed as incorrect because it concerns individuals' subjective feelings. Rokeach (1972) also proposes that individuals possess a belief system that includes the "total universe of a person's beliefs about the physical world, social world, and the self". By using self-disclosure strategy to highlight her prescriptive belief, she attempts to build up some bonds between her and the readers.

\section{Conversational style}

The third persuasive device found in the postings analysed is conversational style which explains the use of informal style of writing. Extract 4 is presented to show how Asma' Nasa uses conversational style to persuade her readers. Figure 3 shows a photo of Asma' standing from afar and looking upward - the photo was taken in Istanbul.

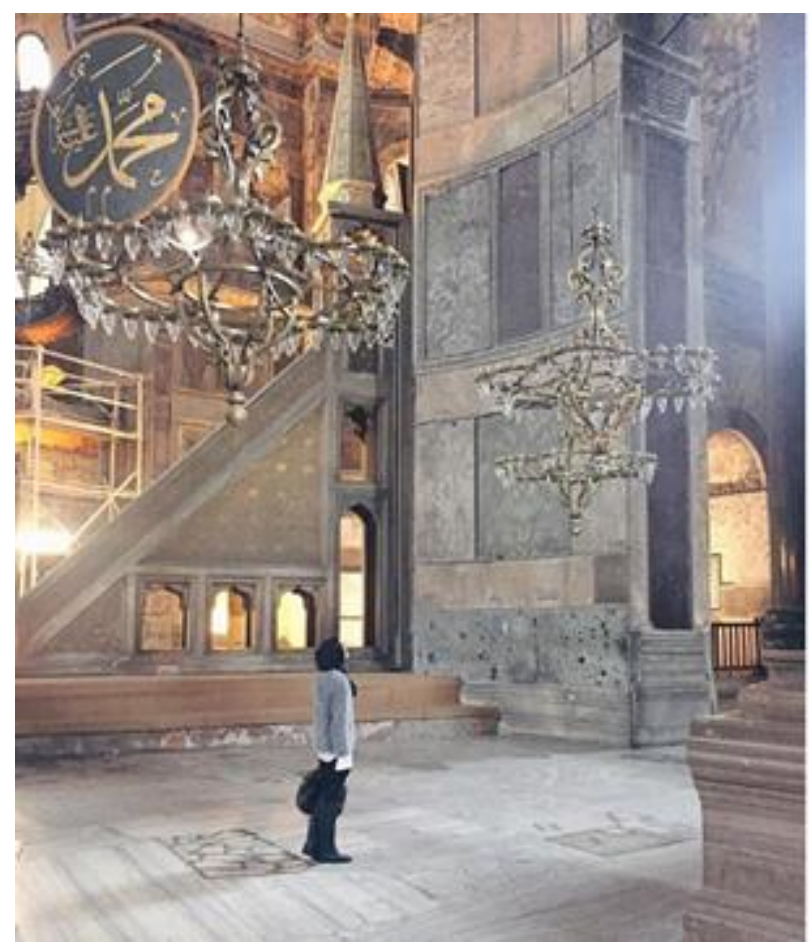
more accepting gentle and understanding of our differences. To share it with others so it brings ease in their life, and surely not to burden. To understand that we are all on different journeys in finding our way back to guidance, and it's okay that some may take longer than another person. Just know that when yourre ready to embrace it with all that you have, it's there waiting for you too.

\section{View all 20 comments}

dymastura $\boldsymbol{\bullet} \boldsymbol{\bullet} \boldsymbol{~ i ~ s e l d o m ~ c o m m e n t ~ o n ~}$ others ig, but i cannot help myself from saying tht il locoocvee all your advices izzuddinnor Such a great lighting: it was so dark when I visited it. Love your post.

2818 likes

wevar 19 von? 
Extract 4 shows an excerpt of the caption used by Asma' from Figure 3.

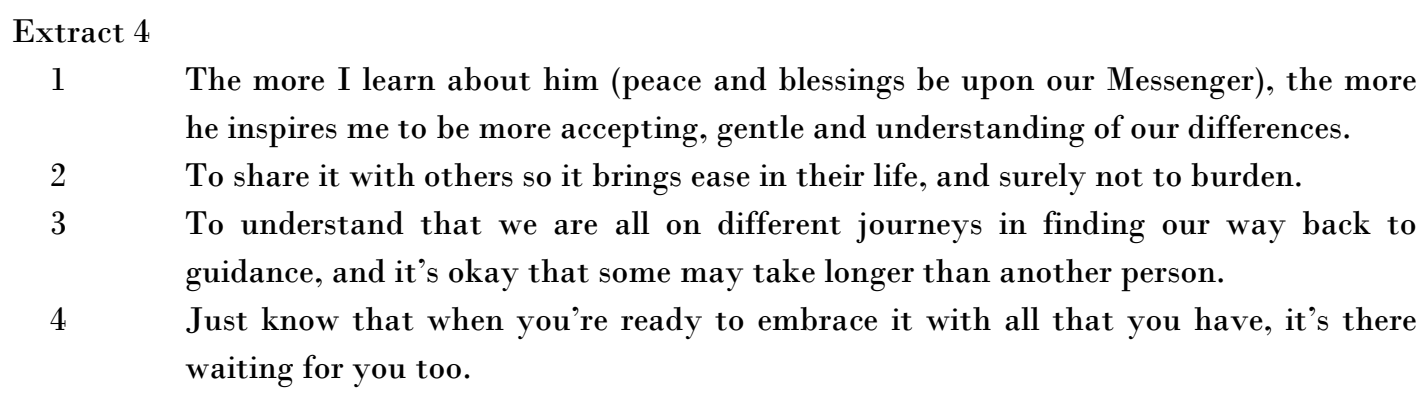

Asma' begins her caption by directly exposing herself, talking about her feelings-giving a personal touch. The use of I-statement (line 1) shows that this is incorporated with her own experience, feelings and thoughts, hence giving the readers an idea of honesty and truthfulness in her writing. It is then followed by a three-point statement that is written in consecutive manner (line 1) to complement the whole sentence and give extra emphasis to the meaning. The way Asma' connected the caption (line 2 and 3 ) gives a finishing touch to her proposed topic in line 1 - she makes full use of emotive phrases such as surely not to burden (line 2) and different journeys (line 3), as well as informal expression such as it's okay (line 3) to appeal to the readers. She then ends her caption with a wellstructured sentence that plays around a strong underlying meaning and the use of pronoun you (line 4) which directly addresses the audience and closes the gap between them, hence creating a greater impact.

Such use of expressions connotes a sense of connectedness on a spiritual level not only with the self but also with the audience. By addressing her sentiment, she managed to capture the heart and attention of her audience. This is made possible with the conversational style strategy in her caption which eliminates if not all but to a certain level, the formal gap between an SMI and their followers in an online setting (Kelleher, 2009).

\section{Synoptic}

The fourth persuasive device found in the postings analysed is synoptic. Synoptic strategy, which summarizes the whole idea, is mainly used by Asma' Nasa to sum up the content of her posting, as presented in Extract 5. Figure 4 shows a photo of Asma' herself, taken from the back, standing next to a palm tree. The photo was captured at The Blue Mosque. 

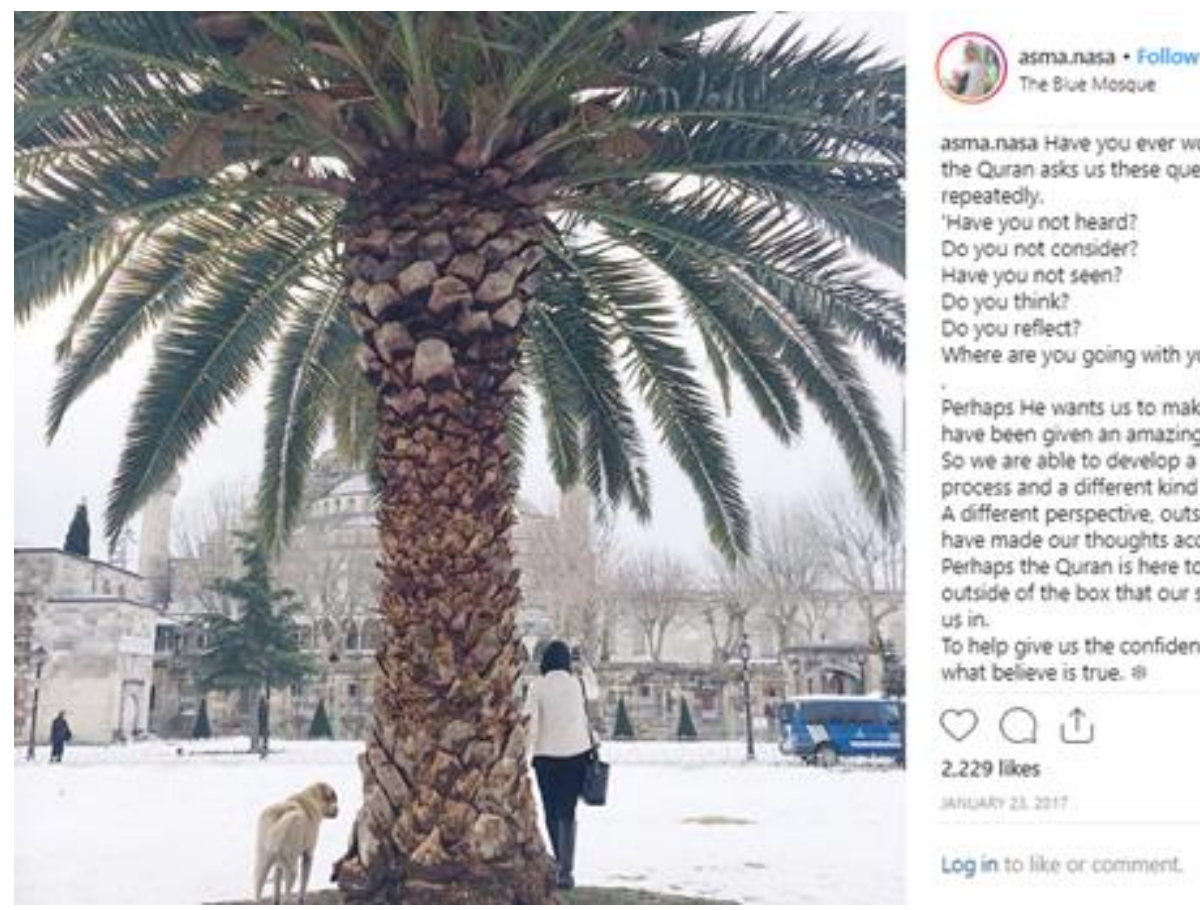

asmanasa Have you ever wondered why the Quran asks us these questions? Often repeatedly.

'Have you not heard?

Do you not consider?

Have you not seen?

Do you think?

Do you reflect?

Where are you going with your life?

Perhaps He wants us to make us realize we have been given an amazing intellect:

So we are able to develop a thought

process and a different kind of awareness.

A different perspective, outside of what we have made our thoughts accustomed to. Perhaps the Quran is here to help us think outside of the box that our society has put us in

To help give us the confidence to go for

what believe is true. 8

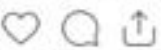

2.229 Ilkes

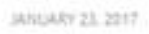

Log in to like or cocriment

Figure 4 Screenshot of Asma's Instagram page

Extract 5 shows an excerpt of the caption used by Asma' from Figure 4.
Extract 5
1
Have you ever wondered why the Quran asks us these questions? Often repeatedly.
2
'Have you not heard? Do you not consider? Have you not seen? Do you think? Do you reflect? Where are you going with your life?'
3 Perhaps He wants us to make us realize we have been given an amazing intellect; So we are able to develop a thought process and a different kind of awareness. A different perspective, outside of what we have made our thoughts accustomed to. Perhaps the Quran is here to help us think outside of the box that our society has put us in. To help give us the confidence to go for what believe is true.

Asma' begins her caption by drawing a general question (line 1) to her followers. She uses the personal pronouns such as you and us (line 1), emphasizing the first-person point of view to provide a much closer and more informal rapport with the audience (Gocheco, 2012). In this situation, the use of rhetorical questions can be seen as an act to trigger the readers towards relating to the topic or the content of the message. Following the prompt is a set of questions which are more specific and entailed to the topic (line 2) which expresses profound truths and demands deep thought from the readers as it has been declared earlier that these questions came from the Quran. In line 3 and 4, what 
has been written by Asma' is closely related to the synecdoche element of the Jamieson's Electronic Eloquence Model (EEM). This is where she synopsizes the whole idea into clear and concise sentences, providing the answers to the preceding questions.

\section{Visual Dramatization}

The final persuasive device employed by Asma' is visual dramatization. Extract 6 is an example of visual dramatization which appears in all her social media postings. Jamieson (1988) refers to visual dramatization as the use of pictures, photographs, sketches and drawings. Visuals are accompanied by captions to help persuaders strengthen their conveying of intended messages. Figure 5 shows a photo of a natural view-merely plants and flowers in Guangdong.
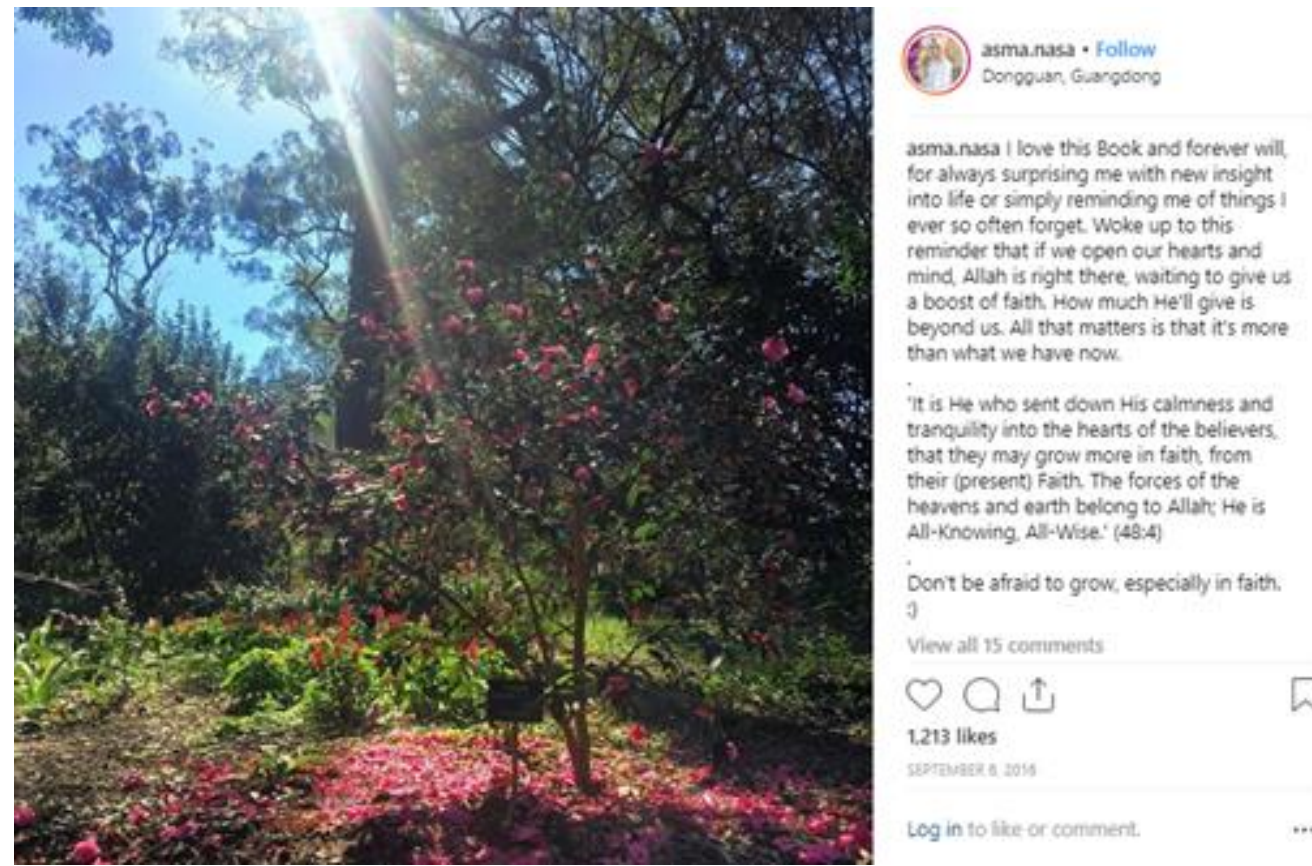

Figure 5 Screenshot of Asma's Instagram page

Extract 6 shows the excerpt of the caption used by Asma' from Figure 5.

\section{Extract 6}

1 I love this Book and forever will, for always surprising me with new insight into life or simply reminding me of things I ever so often forget.

2 Woke up to this reminder that if we open our hearts and mind, Allah is right there, waiting to give us a boost of faith. How much He'll give is beyond us. All that matters is that it's more than what we have now. 
'It is He who sent down His calmness and tranquility into the hearts of the believers, that they may grow more in faith, from their (present) Faith. The forces of the heavens and earth belong to Allah; He is All-Knowing, All-Wise.' (48:4)

In Extract 6, Asma' begins her caption by expressing her feelings-this can be seen from the implementation of pronoun $I$ (line 1), followed by the verb love. She talks about what makes her love a book, which is denoted by the word Book (line 1) with the letter ' $b$ ' is capitalized - to indicate that the book is not of any ordinary books, but a very special one. Readers would then be able to discover what 'book' is exactly Asma' referred to, from the following sentences (line 2 and 3) — the Quran. In line 1 , she mainly uses the first-person point of view such as $I$ and $m e$, however she changes to a second person point of view such as we, our and us in line 2. Asma' then inserts a direct quotation from the Quran (line 3) to support her statement in the previous line. It is known that the quotation in line 3 comes directly from the Quran due to the general use of numbers placed in parenthesis at the end of the sentence that indicate the number of surah and verse-which is widely known in Islam. Reinard (1991) suggested that evidence relevant to the argument seems to be the most persuasive. The interconnection that Asma' creates in her writing from one line to another, as well as how she includes the evidence taken from the Quran to link the idea, has somehow produced a persuasive impact on the readers, especially when she ended the caption with a soft encouragement (line 4). Asma' uses the visual to complement her argument and as shown in the photo, it reflects the intended message about life and blessings from God.

In terms of multimodality discourse analysis (MDA), it is seen that Asma' intends to foreground the tree with the red flowers. This picture serves as a conceptual image, bearing no narrative processes in it. The bush is the carrier of a symbolic attribute process evident in the picture, which is made the most salient by the red flowers and its near-central position. It is made more salient with the sunlight shining down upon the bush, which acts as means of a gesture pointing towards the plant. The bush itself is a proof of life-sprouting and blooming beautiful flowers. As the image is made to supplement her caption, it could be argued that the sunlight received by the plant is akin to God's "boost of faith" to Asma'. Just as sunlight is vital for plants to thrive, bloom and live, God's intervention is needed by Asma' to thrive and survive in this world. The imagery of sunlight fits well with the Quranic verse inserted by her. The sunlight shining down on the plant, giving it energy and life, echoes the essence of the Quranic verse (line 3); a parallelism of our dependence on God as the source of everything.

Visual dramatization, with its use of carefully crafted imagery, manages to capture the audience's attention and provides more context as they relate themselves to Asma' and her postings. Through a multimodal lens, her use of salience and composition are rightfully used in respect to her captions, which supplement meaning to her overall postings. This visual rhetoric shows that trustworthiness and newsworthiness are established to create a memorable vignette for the audience.

Conclusion

In a nutshell, the above discussion concurs with what Hall's (1997) claim, representations are constructed (in Rettberg, 2014) whether it be physical or via online platforms. SMIs construct themselves in a manner that makes their message personal and resonates well with their audience. The 
chosen SMI for this study was seen to construct herself as someone who passionately shares her faith and belief, in relation to Islam. This contributes to the number of followers who share the same interest. Moreover, consistent usage of persuasive strategies such as personification, self-disclosure, conversational, synoptic and visual dramatization became a salient factor in capturing the hearts and interests of current and potential followers. Influencers of social media who promote a brand of lifestyle interact with their followers most successfully notable when they are trustworthy, confident and interactive in their content. Through social media content, social media influencers have broken the wall between the brand of lifestyle and their followers. The existence of SMIs is expected to be increasing in the near future and their roles in the current world are significant in providing the modern generation with controlled influences. The interconnection made in this study has revealed potential strategies for social media users to position themselves as an influencer in the virtual world. In this digital age, attractions through these platforms are inevitable. Such persuasive devices would unconsciously and implicitly blend well across multiple platforms and with persistent practice, SMIs are seemingly to receive recognition from various parties, including brand marketers. Visible implementation of well-strategized postings on social media provides evidence and confidence for the brand marketers to approach these SMIs for any promotional purposes, in which it sets them a role to contribute to social practices. Nevertheless, without the support and feedback of their followers, they are unable to play such an enormous role in this society.

\section{REFERENCES}

Ab, R. R., Hui, L. S., Hui, W. S. S., Azmi, M. N. L., Yusoff, N., \& Azmi, N. J. 2016. Persuasive Elements on the Websites Promoting Fitness Programme. Man in India. 96(12): 5305-5314.

Abidin, C. 2016. Aren't These Just Young, Rich Women Doing Vain Things Online?: Influencer Selfies as Subversive Frivolity. Social Media Society. 2(2): 2056305116641342.

Aldershot: Ashgate.

Aral, S., Dellarocas, C., \& Godes, D. 2013. Introduction to the Special Issue-Social Media and Business Transformation: A Framework for Research. Information Systems Research. 24(1): 313.

Arbit, A. 2010. Flower Symbolism as Female Sexual Metaphor. (Senior Honors Thesis, Eastern Michigan University). Retrieved from http://commons.emich.edu/honors/238.

Borchers, T. A. 2013. Persuasion in the Media Age. 3rd ed. Long Grove: Waveland Press.

Chae, J. 2017. Explaining Females' Envy Toward Social Media Influencers. Media Psychology. 21(2): 246-262. Doi:10.1080/15213269.2017.1328312.

Chen, C. P. 2013. Exploring Personal Branding on YouTube. Journal of Internet Commerce. 12(4): 332347.

Crisp, P. 2005. Allegory, Blending and Possible Situations. Metaphor and Symbol. 20(2): 115-31.

Dobson, A. S. 2015. Postfeminist Digital Cultures: Femininity, Social Media, and Self-Representation. New York, NY: Palgrave Macmillan.

Ehnenn, J. R. 2008. Women's Literary Collaboration, Queerness, and Late-Victorian Culture. 
Fahnestock, J. 2011. Rhetorical Style: The Uses of Language in Persuasion. New York, NY: Oxford University Press, Inc.

Freberg, K., Graham, K., McGaughey, K., \& Freberg L. 2011. Who are the Social Media Influencers? A Study of Public Perceptions of Personality. Public Relations Review. 37: 90-92. Doi: 10.1016/j.pubrev.2010.11.001.

Gocheco, P. M. 2012. Pronominal Choice: A Reflection of Culture and Persuasion in Philippine Political Campaign Discourse. Philippine ESL Journal. 8: 4-25.

Hamilton, C. A. 2002. Mapping the Mind and the Body: On W. H. Auden's Personifications, Style, $36(3): 408-427$.

Hewitt-Taylor, J., \& Bond, C. S. 2012. What e-patients want from the Doctor-patient Relationship: Content Analysis of Posts on Discussion Boards. Journal of Medical Internet Research. 14(6): e155. https://doi.org/10.2196/jmir.2068.

Hookway, N. 2008. Entering the Blogosphere: Some Strategies for Using Blogs in Social Research. Qualitative Research. 8(1): 91-113. https://doi.org/10.1177/ 1468794107085298.

Ioanid, A., Militaru, G., \& Mihai, P. 2015. Social Media Strategies for Organizations Using Influencers' Power. European Scientific Journal. 139-143. Doi:10.4018/978-1-4666-40269.ch013.

Jamieson, K. H. 1990. Eloquence in Electronic Age: The Transformation of Political Speechmaking. Oxford: Oxford University press.

Kelleher, T. 2009. Conversational Voice, Communicated Commitment, and Public Relations Outcomes in Interactive Online Communication. Journal of Communication. 59(1): 172-188.

La Casa, P. de la Fuente, J. García-Pernía, M., \& Cortés, S. 2017. Teenagers, Fandom and Identity. Persona Studies 2017. 3(2). Doi: 10.21153/ps2017vol3no2art648.

Lakoff, G., \& Johnson, M. 1980. Metaphors we Live by. Chicago. IL and London: University of Chicago Press.

Lee. 2016. Malaysians are The Most Active Instagram Users in Asia Pacific. Retrieved from https:/www.thestar.com.my/tech/tech-news/2016/09/29/malaysians-are-themost-activeinstagram-users-in-apac/.

Lucas, C. 2001. The Sociolinguistics of Sign Languages. Cambridge: Cambridge University Press.

Marwick, A. E. 2015. Instafame: Luxury Selfies in the Attention Economy. Public Culture. 27: 137160.

O'Brien, C. 2011. The Emergence of the Social Media Empowered Consumer. Irish Marketing Review. 21(1/2): 32-40.

O'Halloran, K. L. 2011. Multimodal Discourse Analysis. Continuum Companion to Discourse Analysis. 120-137.

Pirini, J., Matelau-Doherty, T., \& Norris, S. 2018. Multimodal Analysis. In The Palgrave Handbook of Applied Linguistics Research Methodology (pp. 639-658). Palgrave Macmillan, London.

Reinard, J. C. 1991. Foundations of Argument: Effective Communication for Critical Thinking. Dubuque, IA: William C. Brown.

Rettberg, J. W. 2014. Seeing Ourselves through Technology: How We Use Selfies, Blogs and Wearable Devices to See and Shape Ourselves. New York, NY: Palgrave Macmillan. 
Rokeach, M. 1972. Beliefs, Attitudes and Values: A Theory of Organization and Change by Milton Rokeach. San Francisco: Jossey-Bass.

Saul, H. 2016. Instafamous: Meet the Social Media Influencers Redefining Celebrity. The Independent. Retrieved from https:/www.independent.co.uk/news/people/instagram-modelnatasha-oakley-iskra-lawrence-kayla-itsines-kendall-jenner-jordyn-woods-a6907551.html.

Stiff, J. B., \& Mongeau, P. A. 2003. Persuasive Communication. 2nd ed. New York, NY: The Guilford Press.

Tengku Siti Aisha Tengku Mohd Azzman Shariffadeen, \& Aini Maznina A. Manaf. 2019. CelebrityFan Engagement on Instagram and Its Influence on the Perception of Hijab Culture Among Muslim Women in Malaysia. Jurnal Komunikasi: Malaysian Journal of Communication. 35(1): 286-302.

Wan Hanafi, W. A. A., Ithnin, N., \& Ab. Rashid, R. 2017. An Analysis of Parenting Blog through the Lens of Electronic Eloquence Model (EEM). In N. H. Abdullah, N. J. Azmi, S. Z. Yusoff, S. H. Ayub \& M. R. Hamzah (Eds.). Analects of Communication Studies (pp. 32-45). Kuala Terengganu, Malaysia: Penerbit Universiti Sultan Zainal Abidin.

West, R. L., \& Turner, L. H. 2010. Introducing Communication Theory: Analysis and Application. Boston: McGraw-Hill.

Wignell, P., Chai, K., Tan, S., O’Halloran, K., \& Lange, R. 2018. Natural Language Understanding and Multimodal Discourse Analysis for Interpreting Extremist Communications and the ReUse of These Materials Online. Terrorism and Political Violence. 1-26. 